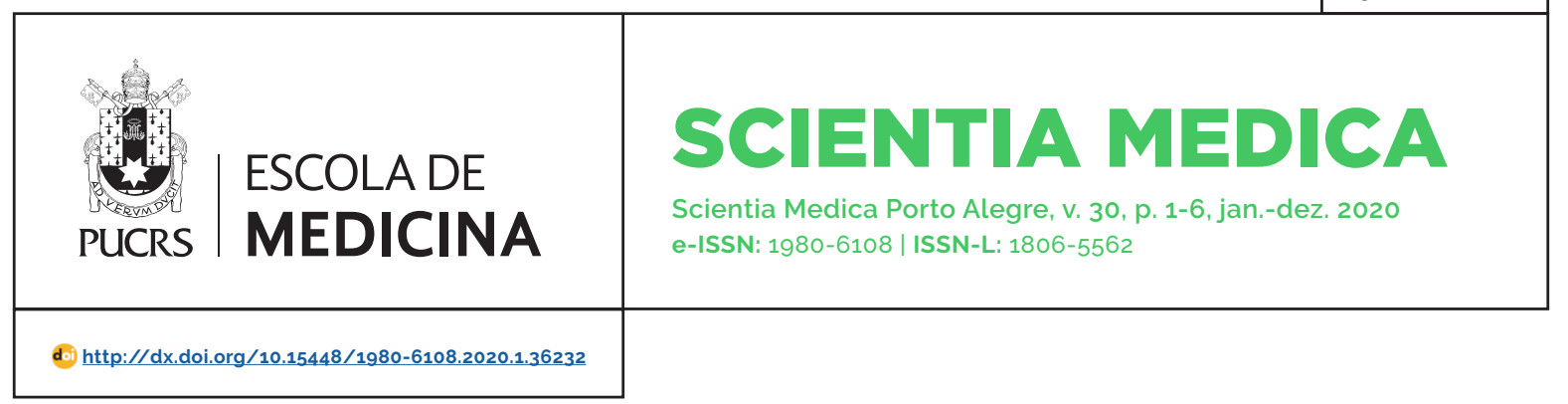

HEALTH SCIENCES EDUCATION

\title{
Self-Regulated Learning: the essential factor for understanding and improving academic and clinical performance
}

\author{
Aprendizagem auto-regulada: o fator essencial para entender e melhorar o \\ desempenho acadêmico e clínico
}

\section{John Sandars ${ }^{1}$}

orcid.org/0000-0003-3930-387X

john.sandars@edgehill.ac.uk

Recebido em: 30 out. 2019

Aceito em: 15 nov. 2019

Publicado em: 25 mar. 2020 ,
Abstract: There is increasing interest in the importance of Self-Regulated Learning for the improvement of academic and clinical performance. Self-Regulated Learning is a dynamic and cyclical metacognitive process that coordinates an individual's skill (techniques) and will (motivation) to achieve a clearly defined task. There are differences in key Self-Regulated Learning processes between high and low performers, especially goal setting and self-monitoring. Formative feedback on the use of key Self-Regulated Learning processes, which can be identified using microanalysis before, during and after an individual performs a specific task, can lead to improved performance. There is increasing awareness of the importance of both the social and educational environment on the use of Self-Regulated Learning, including the essential influence of the teacher.

Keywords: Education; learning; metacognition; formative feedback

Resumo: O interesse sobre a importância da aprendizagem autorregulada para o desempenho acadêmico e clínico vem aumentando. A aprendizagem autorregulada é um processo cognitivo dinâmico e cíclico que integra a habilidade e motivação do aluno para realizar uma tarefa definida. Existem diferenças importantes para o processo da aprendizagem autorregulada para alunos de baixo e alto desempenho, especialmente em relação ao estabelecimento de metas e ao automonitoramento. Feedback formativo nos processos chaves da aprendizagem autorregulada pode ser identificada utilizando a microanálise, antes, durante e depois da realização uma tarefa especifica pode melhorar o desempenho. Ainda, existe um aumento na percepção da importância da aprendizagem autorregulada tanto no ambiente social quanto educacional, incluindo a importância do professor.

Palavras-chave: Educação; aprendizagem, metacognição; feedback formativo

Abbreviations: SRL, Self-Regulated Learning; SDL, Self- Directed Learning.

\section{INTRODUCTION}

Over the last twenty years there has been increasing interest in the use of Self Regulated Learning (SRL) over the broad spectrum of education, from young children to life-long learning. This trend has also occurred in medical education, with increasing interest in SRL and its major influence on both academic and clinical performance. This article will provide a practical introduction for all medical educators who are interested in applying SRL to understand and improve academic and clinical performance. Essential features of the article include critical discussions about what is SRL, the importance of SRL for improving academic and clinical performance, 
how to effectively provide interventions that use $\mathrm{SRL}$, and the future directions for using $\mathrm{SRL}$ in medical education.

\section{What is Self-Regulated Learning?}

The effective performance of any task, academic or clinical, requires a constant dynamic and cyclical adjustment of both skill and will to the demands of the task [1]. The skill is the technique required to achieve the task, such as the stages of mathematical problem solving for an academic task or the various steps in the examination of the cardiovascular system for a clinical task. The will is the important internal motivational aspect of performance that ensures that the individual can fully mobilise their thoughts and energy to engage with the task. Most educational theories, and educational interventions, have a focus on only these two aspects of performance but the successful achievement of the task requires an individual to have an overall mental picture of an optimum performance, with a dynamic process that constantly fine tunes their skill and will to achieve the task. This process of fine tuning, that consists of monitoring and adjustment of performance, has been called metacognition [2]. Metacognition is central to SRL, with the constant and cyclical self-monitoring and self-regulation of performance to ensure that the skill and will being employed by the individual are optimal for achieving the task. An internal feedback loop is established by the individual to effectively achieve the task and this process is similar to the wellknown physiological homeostasis model.

There are several models of SRL but they all share many common features, especially the recognition that metacognition is central to effective performance [3]. The model described by Zimmerman has been widely adopted in both general and medical education to understand and improve both academic and clinical performance [4]. In Zimmerman's process model of SRL, there are three main phases of a performance to achieve a specific task:
- Before performance: the individual sets a specific goal based on the specific task to be achieved, selects an appropriate technique to achieve this goal (skill) and motivates themselves using self-efficacy beliefs (will). Self-efficacy beliefs are the extent to which an individual considers that they can achieve a specific goal.

- During performance: the individual constantly self-monitors their performance to ensure that the chosen technique (skill) and motivation (will) is appropriate to achieve the task.

- After performance: the individual self-regulates their performance by making adaptive changes to their technique (skill) and motivation (will) to ensure that their performance will achieve the task. An important aspect in this phase are the attribution beliefs that the individual has about the reasons for being successful, and unsuccessful, in achieving the desired task.

There is often an interchangeable use of the terms Self-Directed Learning (SDL) and SRL and this can lead to confusion by medical educators but there are some important differences [5]. SDL has its origins in adult learning theory, with a general focus on lifelong learning and the individual's internal motivation to the performance and achievement of a wide variety of different tasks. This is in contrast to SRL, which has its focus on an individual's performance to achieve a specific task. An individual that has high SDL will need to be effective in SRL. However, an individual who consistently uses a variety of key SRL processes when successfully responding to a range of different of tasks may not show high SDL since their response is only to factors that impose external motivation, such as an assessment.

\section{The importance of Self-Regulated Learning for performance}

Research across a wide variety of academic and clinical performance scenarios has consistently shown differences in key SRL processes between individuals that are successful, and unsuccessful, 
in performing the different tasks [6] [7] [8]. These tasks range from learning biomedical sciences and maximising learning in clinical settings to performing clinical reasoning and procedural skills. The main differences appear to be in the extent to which an individual sets clear and specific goals at the beginning of a performance and also the extent to which the individual constantly self-monitors their performance. Successful achievement of a task requires setting clear and specific goals with attribution beliefs that focus on factors that can be controlled by the individual, such as the choice of technique. In contrast, unsuccessful achievement of a task is associated with the setting of vague goals and the attribution of lack of success to factors outside individual control, such as bad luck. Self-monitoring of performance is essential to make the dynamic and cyclical adaptive self-regulation changes to the choice of technique and to maintain motivation through positive self-efficacy beliefs.

\section{Using Self-Regulated Learning interventions to improve performance}

An important reactive approach to develop key $\mathrm{SRL}$ processes to improve academic and clinical performance is formative feedback on the use of these processes during a performance to achieve a specific task. In a review of effective formative feedback interventions, Hattie and Timperley highlight the additional importance of feedback on an individual's use of key SRL processes in combination with the more frequently provided feedback on the achievement of the task and the specific use of factors related to skill (technique) and will (motivation) [9]. Effective formative feedback interventions focus on the initial identification of the range of factors that an individual is both successfully employing, and not employing, to achieve the task. After the initial identification, the individual can be informed about the changes required in the various factors to ensure successful completion. The long term impact of formative feedback on performance will only be achieved if the individual has the opportunity to integrate and embed their use of new factors, including key $\mathrm{SRL}$ processes, into future performances. This embedding phase of formative feedback can be provided using deliberate practice and coaching support from a medical educator. The combined formative feedback approach has been called SRL-enhanced feedback [10].

Formative feedback on the use of key SRL processes requires the initial identification of the extent to which an individual uses these processes during a performance. An essential consideration for the identification of key SRL processes is that these processes are related to a specific task, which is delineated by a clearly defined length of time [11]. The length of time over which key SRL processes are employed by an individual can be short, such the few minutes required to complete a mathematical problem or insert a venous cannula

Identification of the use of key SRL processes over a short and specific task is easily performed using SRL microanalysis, which uses a modified talk-aloud protocol of a series of questions that are asked by the educator both before, during and after performing the task [10]. Examples of these questions in relation to the phases of SRL when inserting a venous cannula are:

- Before performance: "Do you have a particular plan or approach that you will use to insert the cannula?" This question identifies the extent to which the individual has a clear goal but also identifies both the skill (technique) and will (motivational self-efficacy beliefs) that are going to used be by the individual to achieve the task.

- During performance: "Is your approach going as expected?" This question identifies the extent to which the individual is self-monitoring their performance. It is only by self-awareness of whether the desired task is likely to be achieved or not that adaptive changes in both skill (technique) and will (motivational self-efficacy beliefs) can be made by the individual. 
- After performance: "Do you need to make any changes in the way that you will insert the cannula?" This question identifies the extent to which the individual will make adaptive changes to their future performance.

Further description and discussion of the range of different questions that can be asked using a SRL microanalysis of a clearly defined task and how the answers can be used to provide formative feedback is provided in a highly practical article by Leggett, Sandars and Roberts [10]. The SRL microanalysis approach can also be used for the identification and formative feedback of key SRL processes used during a task that has a longer duration, such as the management of an acutely ill patient, but this requires the performance of the task to be broken down into a series of clearly defined sub-tasks.

Other methods can be used to identify key $\mathrm{SRL}$ processes for the provision of formative feedback, such as structured interviews or questionnaires after a task has been performed, but these are prone to recall bias and can lead to disagreements between learners and their tutors who are providing feedback [4]. Also, structured interviews or questionnaires are often used to identify the use of key SRL processes by an individual performing a task over a longer period of time, such as an academic module or a whole clinical attachment. These methods identify a general application of key SRL processes by an individual but the findings may not closely correlate with the more situational use of key SRL processes identified when approaching a range of different specific tasks [12].

The attention of formative feedback on key $\mathrm{SRL}$ processes can have an enabling effect on individuals since the focus is on specific processes that an individual is doing, or not doing, and that performance is related to the appropriate use of these processes. This is in contrast to many feedback interactions that appear to focus on the perceived attributes of the individual, such as mental ability, leading to blame and lack of motivation in the individual.

Proactive development of key SRL processes can be provided by direct instruction, especially as an integral component of 'learning to learn' courses [13]. An example is the Pause 2 Learn approach which uses an initial questionnaire to stimulate self-reflection on the individual's use of key SRL processes across several recent tasks and this is followed by targeted group and individual development of key SRL skills [14].

An interesting and important research finding for busy medical educators is that instruction and development of only one key SRL process can be effective for improving performance [15], with examples that include goal setting for learning in clinical environments and self-monitoring using calibration workbooks for learning biomedical science [8] [16]. However, the full potential of formative feedback on key SRL processes will only be achieved if it is provided as SRL enhanced feedback, with integration of feedback on the achievement of the task and the specific use of factors related to skill (technique) and will (motivation).

\section{Future directions for Self-Regulated Learning in medical education}

Research suggests that there is low correlation between measures of an individual's use of some key SRL processes as identified by SRL microanalysis of a specific task compared with self-reported recall after the performance of the same task. However, there appears to be good correlation with the key $\mathrm{SRL}$ process of selfmonitoring [17]. This important finding highlights the importance of metacognition to inform medical educators about how to identify and develop SRL in their learners.

SRL -enhanced feedback, that integrates external feedback on the use of key SRL processes (which can be identified by microanalysis) with other important factors of a performance (skill and will), has potential for wider application within medical education for both academic and clinical situations. However, the potential is likely to be limited unless medical educators develop and implement not only their formative feedback approach to include SRL -enhanced feedback but to also to ensure that their overall approach to providing formative 
feedback is congruent with best practice.

The use of key SRL processes by an individual appears to be highly situational, being associated with both a specific task and their performance within a wider social and educational environment. There is increasing interest in the importance of co-regulation of the performance to achieve a specific task, with a group of individuals collaboratively using key SRL processes to achieve a common task [18]. This social aspect of SRL has important implications for developing teams, with new observational methods being required to identify how individuals contribute to the effectiveness of performing a specific task. There is an exciting potential for developing particular team members to become 'SRL coaches' who can provide dynamic external feedback during a complex clinical performance.

The educational environment, which includes the teaching and assessment approaches, has an important influence on both the immediate and long-term use of SRL by an individual [19]. Both approaches should be aligned to ensure that the key SRL processes are developed and assessed by the medical educator, with a focus on the formative feedback on the individual's use of key SRL processes. The aim of external feedback is to help the individual to enhance their internal self-feedback approach. Research into the remediation of struggling students has highlighted the importance of developing and internalising key SRL processes for long-term impact on performance [20]. Many approaches to remediation only focus on developing a particular skill, or technique, to achieve the short-term task of passing the next assessment. However, effective learners need to develop the key SRL processes to coordinate a variety of skills to meet the demands of future different tasks and this requires opportunities for deliberate and repeated practice to ensure external feedback becomes internalised to provide the essential internal feedback system that has a focus key SRL processes.

\section{Conclusion}

The increasing interest in the use of Self Regulated Learning (SRL) to understand and improve performance in both general and medical education has led to increasing awareness of its potential, especially when formative feedback is provided that integrates feedback on the use of key SRL processes with the other factors of task completion and use of skill and will. There are several important areas for future development and research in the use of SRL in medical education, including the co-regulation of performance and embedding the various facets of SRL across the curriculum, from basic medical education to postgraduate medical education and continuing medical education.

\section{References}

[1] Sandars J. Patel R. Using personalized teaching and learning to improve clinical performance. $\mathrm{Br} \mathrm{J}$ Hosp Med (Lond).2018;79(2):102-15

[2] Shaughnessy MF, Veenman M, Kennedy CK. Meta-cognition: A recent review of research, theory, and perspectives. Hauppauge, New York: Nova Publishers; 2008

[3] Panadero E. A review of self-regulated learning: Six models and four directions for research. Front Psycol. 2017;8:422. https://doi.org/10.3389/ fpsyg.2017.00422

[4] Zimmerman BJ. Investigating self-regulation and motivation: Historical background, methodological developments, and future prospects. Am Educ Res J. 2008;45(1):166-83. https://doi. org/10.3102/0002831207312909

[5] Gandomkar R, Sandars J. Clearing the confusion about self-directed learning and self-regulated learning. Med Teach. 2018; 40(8):862-3. https://doi.org/1 $0.1080 / 0142159 \times .2018 .1425382$

[6] Lucieer SM, Jonker L, Visscher C, Rikers RM, Themmen AP. Self-regulated learning and academic performance in medical education. Med Teach. 2016:38(6):585-93. https://doi.org/10.3109/014215 9x.2015.1073240

[7] Brydges R, Manzone J, Shanks D, Hatala R, Hamstra SJ, Zendejas B, Cook DA. Self-regulated learning in simulation-based training: a systematic review and meta-analysis. Med Educ. 2015;49(4):368-78. https:// doi.org/10.1111/medu.12649 
[8] van Houten-Schat MA, Berkhout JJ, van Dijk N, Endedijk MD, Jaarsma AD, Diemers AD. Self-regulated learning in the clinical context: a systematic review. Med Educ. 2018; 52(10):1008-15. https://doi. org/10.1111/medu.13615

[9] Hattie J, Timperley H. The power of feedback. Rev Educ Res. 2007:77(1):81-112.

[10] Leggett H, Sandars J, Roberts T. Twelve tips on how to provide self-regulated learning (SRL) enhanced feedback on clinical performance. Med Teach. 2019; 41(2):147-51. https://doi.org/10.1080/014215 9x.2017.1407868

[11] Karabenick SA, Zusho A. Examining approaches to research on self-regulated learning: conceptual and methodological considerations. Metacogn Learn. 2015; 10(1):151-63. https://doi.org/10.1007/ s11409-015-9137-3

[12] Follmer DJ, Sperling RA. Examining the Role of Self-Regulated Learning Microanalysis in the Assessment of Learners' Regulation. J Exp Educ. 2019;87(2):269-87. https://doi.org/10.1080/00220973 .2017 .1409184

[13] Hofer BK, Yu SL. Teaching self-regulated learning through a" Learning to Learn" course. Teach Psychol. 2003; 30(1):30-3. https://doi.org/10.1207/ s15328023top3001_05

[14] Sandars J. Pause 2 Learn. Med

Educ.2010;44(11):1122-3.

[15] Cleary TJ, Zimmerman BJ, Keating T. Training physical education students to self-regulate during basketball free throw practice. Res Q Exerc Sport. 2006; 77(2):251-62. https://doi.org/10.1080/02701367 .2006 .10599358

[16] Leggett H, Sandars J, Burns P. Helping students to improve their academic performance: a pilot study of a workbook with self-monitoring exercises. MedTeach. 2012;34(9):751-3. https://doi. org/10.3109/0142159x.2012.691188

[17] Callan GL, Cleary TJ. Multidimensional assessment of self-regulated learning with middle school math students. Sch Psychol Q. 2018 Mar;33(1):103-11. https://doi.org/10.1037/spq0000198

[18] Rich JV. Proposing a model of co-regulated learning for graduate medical education. Acad Med. 2017:92(8):1100-4. https://doi.org/10.1097/ acm.0000000000001583

[19] Broadbent J, Poon WL. Self-regulated learning strategies \& academic achievement in online higher education learning environments: A systematic review. Internet High Educ. 2015;27:1-3. https://doi. org/10.1016/j.iheduc.2015.04.007

[20] Andrews MA, Kelly WF, DeZee KJ. Why does this learner perform poorly on tests? Using self-regulated learning theory to diagnose the problem and implement solutions. Acad Med. 2018:93(4):612-5. https://doi.org/10.1097/acm.0000000000001422

\section{CORRESPONDENCE}

\section{John Sandars}

Medical School, Faculty of Health, Social Care and Medicine, Edge Hill University. St Helens Road, Ormskirk, L39 4QP, United Kingdom 